\title{
The design of fire retardant textile products: An exploration of design characteristics
}

\author{
Lynn M. Boorady / State University of New York College at Buffalo / Buffalo / USA \\ Shu-Hwa Lin / University of Hawaii at Manoa / Manoa / USA
}

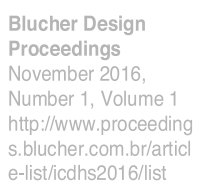

\begin{abstract}
This study examined the processes involved in the design of fire retardant textile products with an emphasis upon processes undertaken by designers' who are committed to a design for career and volunteer fire fighters. Qualitative and quantitative research was undertaken with career and volunteer firefighters in mainland United States, Hawaii and Taiwan. Analysis revealed the need for a garment less bulky than traditional bunker gear and yet still protective at a fire scene. Researchers followed the six themes or stages in the design process for protective apparel: resources and research, consumer need, inspiration, creative exploration, product samples, and design completion.

Prototypes were developed based on the information gathered through research and the design process. Application of the resulting garment is expected in lower risk environments (vehicle accidents, extraction) or by officers who are not expected to enter a structure fire but must be present at the fire scene.
\end{abstract}

\section{Keywords}

Fire retardant experience, design-process, protective apparel

\section{Introduction}

In 2013, there were an estimated 1,140,750 fire fighters in the United States, approximately 354,600 career and 786,150 volunteer fire fighters (United States Fire Administration, 2013). There are about 13,000 fire fighters in Taiwan (National Fire Agency, 2015). Fire fighters, on a daily basis, respond to a number of diverse emergency calls including fire, health aid, hazardous materials and vehicle accidents. Fire fighters may also encounter a variety of weather conditions, from freezing to extremely hot/humid in addition to the intense heat of a fire. The creation of fire fighter personal protective equipment (PPE) must take in to account all of these varying conditions while providing protection as laid out in the National Fire Protection Agency's established standards (NFPA, 2013).

The purpose of this study was to develop a compact and easy to store prototype design for emergency response purposes as an alternative to bunker gear. This garment was envisioned to be an upper torso covering such as a jacket or shirt with a hood.

\section{Resources and research}

As not all calls fire fighters go on involve entering a burning building, a secondary garment which would provide minimal protection from fire was deemed useful. As firefighter bunker gear is designed with enough protection to protect the wearer in otherwise unsurvivable conditions, firefighters may be overprotected, and even negatively affected, by current gear. On average the basic set of gear (jacket or coat, pants, boots, helmet, gloves and air pack) weigh approximately 45 pounds. However, when you add in the different tools (axe, radio, hose, ladder, flashlight, etc.) needed for a particular job the extra weight can jump up to 75 or even 100 extra pounds of equipment.

\section{Consumer need}

Qualitative and quantitative research was undertaken through questionnaires and focus group sessions with more than 300 career and volunteer firefighters in mainland United States, Hawaii and Taiwan. Data on specific issues 
were collected through follow-up intensive interviews with career and volunteer fire fighters. Participants in the focus groups expressed concern about how their current gear affects them both physically and physiologically, especially since the majority of firefighter fatalities are caused by heart attacks (USFA, 2013). The focus groups discussed that their current gear creates additional heat stress, muscle fatigue and reduced mobility due to the weight and bulk. Current bunker gear has very limited methods of releasing heat build-up causing the body temperature to rise which causes extreme discomfort and could lead to heat stress. In addition to this, the bunker gears inner thermal barrier traps heat and moisture which can take days to dry out - leaving the firefighter to wear wet gear. In the winter, this can cause the gear to freeze when outside a fire and heat to build up faster when in the fire all of which reduces the level of protection.

In follow up interviews, the fire fighters all agreed that their current PPE over-prepares them for almost all of the non-fire calls. They noted that temperature, perspiration rate and heart rate all increased when they were wearing their PPE. One participant noted that "street clothing is often more suitable" when on a nonfire call. Mobility was also a concern while wearing their PPE and most participants attributed this to the bulkiness of the apparel.

Participants also complained about burns around the face and ears due to the shifting of the protective hood. The current hoods are made of a knit fabric which loses it dimensional stability over the life of the garment causing gaping around the face when worn.

In conversations with fire administrators, it became apparent that many of them do not necessarily wear bunker gear on a fire scene as they would usually be in command of the action at the site. However, they stated that sometimes they need to get closer than they are comfortable without wearing protection if their presence is required at a certain location. These participants wanted more protection but not wear a full set of bunker gear.

\section{Inspiration}

Research is vital to all design, particularly in designing PPE. At this point, the process was exploratory - keeping in mind the objectives of the final design and looking for any possible solutions or ideations. The research started very broadly looking at all varieties of garments used in a variety of working conditions. The designer/researchers separately looked at a variety of sources for inspiration including the history of firefighting bunker gear, bunker gear used in different parts of the world, athletic gear and even street wear.

The designer/researchers spent hours discussing alternatives to the fire fighters PPE for nonfire responses. At this point, the research narrowed and became more in-depth as the discussion led to a variety of possible solutions. It was determined that an alternative garment could be developed which the fire fighter could wear as an alternative to suiting up in full bunker gear.

When searching for inspiration, the designers kept in mind some basic requirements for the design based on participant responses. The new item must have fire protection for the head, arms and upper torso, pocket for the radio and gloves, easy to don/doff and, in an emergency, be worn under the protective coat.

This stage also required the research and gathering of different materials which could of be use in our design. The fabrication had its own set of requirements, though not as stringent at what is required for bunker gear. The fabric was required to be heat and flame resistant, not bulky and easy to care for in a home environment. The selection of fabric was deemed the most important as it would be essential in the success of the final product.

\section{Creative exploration}

Watkin's (1984) model of product design and development provided a context by which to explore inclusion of environmental performance criteria within the design process. Once a variety of inspirations were found and once it felt the research was exhausted, each designer shared their research and discussion took place as to possible avenues to explore more in depth. The designers individually sketched out dozens of ideas based on the research and discussion. These ideas were compiled and put into categories based on particular attributes such as closure, pockets, hood style. The designers discussed each idea within each category determining if the design met the criteria set forth in the original statement. If the design did not hold to the statement, it was set aside.

Ideas such as building in joint articulation at the elbow level were discussed but determined not to be necessary with the use of lighter weight and less bulky material. Reflective tape was also deemed not a requirement on the first model as the garment was not intended to be worn within a structural fire, though this may be 
revisited later based on feedback.

A variety of closures were discussed. Fire fighters had mentioned that zippers can be difficult to engage and then pull up when trying to don items rapidly and hook/loop tape was deemed not durable enough (particularly after numerous washings).

Pocket placement was important to the participants. Though many stated that their pants pockets were used more frequently for tools, they required at least one pocket on the upper torso for their two-way radio.

It was determined that the hood would need to fit under the helmet and allow for movement of the neck and shoulders. The area around the face would need special attention to ensure good fit to reduce /eliminate burns and the fabric should have good dimensional stability so that the protection would not be reduced after washing and wearing.

We determined that the fabric should be constructed as a knit to allow for some allowances in fit and to incorporate the hood into a single garment. Numerous fabrics were researched to find a fabric which was flame and heat resistant and had a soft hand. Pyron ${ }^{\circledR}$ was chosen for its superior performance against aramids and flame retardant polyester. Pyron ${ }^{\circledR}$ is an oxidized polyacrylonitrile (OPAN) carbon fiber developed and trademarked by the Zoltek Company headquartered in Missouri, USA (Zoltek, 2015). Pyron® does not melt, burn or drip and completely blocks flame even after being subjected to a $1250^{\circ} \mathrm{c}$ flame test (Zoltek, 2015). Even after exposure to flame, it will retain its dimensional stability and soft hand. It is currently being used in racing and stunt apparel as well as welding aprons.

Once the fabric was identified, it was decided to create two prototypes and get feedback on each before proceeding.

\section{Product samples / prototypes}

Two prototypes were developed based on the designed from the creative exploration. A third design was developed when one of the designers found an issue with the shoulder shape of the garments and decided to change it.

Male participants were recruited to try on the garment and an activity assessment was performed. Participants gave feedback on fit, mobility, ease of donning and doffing as well as protective functions. Specific movement assessment was conducted to determine if the jacket interfered with any performance tasks. Pockets were checked to determine if the size and shape were suitable for the required instruments, such as a twoway radio, and if the location of the pocket allowed the wearer easy access to their equipment.

Qualitative research was done at this phase through individual interviews with the participants in order to ascertain any wearing issues that could not be observed. One major theme that emerged was that the lightweight fabric chosen for the design did not feel protective enough to the wearer and they stated that they would not feel safe.

Based on feedback from the participants, additional iterations of the design need to be developed. A full test is expected to be completed in 2017 to fine tune the design based on wearer's feedback. It is expected that the test will be conducted in the field during a practice fire drill in order to complete a more in-depth observation of the success or failure of the design.

A final evaluation of the garment would include determining final cost and manufacturing considerations as well as fit and sizing.

\section{Conclusion}

This study followed the six themes or stages in the design process: resources and research, consumer need, inspiration, creative exploration, product samples, and design completion to develop upper torso protection for a fire fighter not actively engaged in a fire situation. While more studies need to be conducted in order to finalize the design, we have shown how the process works for PPE. This process offers a structure to help identify a variety of resources, ideations and can help lead to a successful conclusion.

This study also shows the importance of soliciting end-user support and guidance in order to create a successful end product. By including the end-user in the design process by identifying a problem and providing feedback, it creates a more meaningful experience and can lead to increased satisfaction with the end product.

As fire fighters have a strong sense of tradition, adoption of this garment may be difficult. The 
change from long jacket to the current coat/pant combination took some departments almost 20 years to adopt. The design may need to change to fit the wearer's perception of what a fire fighter "should" wear. Secondly, as our first prototype feedback indicated, education must be done to ensure the population that lightweight can be protective.

Future research will include additional prototypes and wear testing. Through this process of developing prototypes and soliciting constant feedback, it is hoped a solution will be forthcoming. Additionally, as textiles advance in their fire protection properties, additional research on the entire bunker gear ensemble should be ongoing to help reduce the weight and bulk yet keep the protection constant or improving.

\section{References}

National Fire Protection Association, NFPA 1971 Standard on Protective Ensembles for Structural Fire Fighting and Proximity Fire Fighting, National Fire Protection Association, Quincy, 2013 Edition.

National Fire Agency. (2008) Ministry of the Interior. Retrieved June 15, 2015 from http://www.nfa.gov.tw/main/index.aspx?ID=2.

United States Fire Administration. In Fire Statistics: Firefighters, 2013. Retrieved June 14, 2015 from http://www.usfa.dhs.gov/downloads/pdf/10_fatality_summary.pdf.

Zoltek. (N.D.) Information sheet on Pyron®. Retrieved June 1, 2015 from http://zoltek.com/wpcontent/uploads/2011/07/Information-Sheet-Pyron.pdf.

\section{Biographical note}

Lynn M. Boorady, Ph.D. is an Associate Professor and Chair at SUNY - Buffalo State College in the Fashion and Textile Technology department. She is a Fulbright Scholar and invited speaker in her areas of expertise which include personal protective equipment, issues in sizing and fit and 3D body scanning.

Dr. Shu-Hwa Lin is an Associate Professor in the Fashion Design \& Merchandising program at the University of Hawaii at Mānoa. Her research examines new forms of textiles and clothing that contribute to the health, protection, comfort, utility, and appearance concerns of individuals and groups with special needs. 